\title{
Effect of maternal lorazepam on the neonate
}

\author{
A G L WHITELAW, A J CUMMINGS, I R MCFADYEN
}

\begin{abstract}
Fifty-three neonates born to 51 mothers treated with lorazepam were followed up for five days after delivery. Lorazepam had been given by mouth to 35 mothers and intravenously to 16 .

In general, maternal plasma concentrations of lorazepam were higher than the corresponding cord plasma concentrations. Cord plasma concentrations exceeding $45 \mu \mathrm{g} / 1$ were associated with three-quarters of the infants requiring ventilation at birth. Neonates conjugate lorazepam slowly to the pharmacologically inactive glucuronide, which is then excreted in the urine, where it is detectable for over seven days. Though lorazepam was detectable in breast milk, the maximum amounts that an infant could absorb would be pharmacologically insignificant. Full-term neonates whose mothers had received oral lorazepam had no complications apart from slight delay in establishing feeding, which in seven out of 29 cases was associated with relatively large doses of lorazepam. Intravenous lorazepam for severe hypertension was associated with significantly low Apgar scores, need for ventilation, hypothermia, and poor suckling. Preterm babies whose mothers had been given lorazepam by either route had a high incidence of low Apgar scores, need for ventilation, hypothermia, and poor suckling. These babies had lower Apgar scores than those whose mothers had received diazepam, but the diazepam group were heavier and more mature. Lorazepam was an effective sedative and anxiolytic by either route, and there were no eclamptic fits among the lorazepam-treated patients.
\end{abstract}

The effects of lorazepam on neonates indicate that its intravenous use at any stage in pregnancy and oral use before 37 weeks should be restricted to hospitals with facilities for neonatal intensive care.

\section{Introduction}

Lorazepam (Ativan) is a benzodiazepine which has effective anticonvulsant, anxiolytic, and amnesic actions. Its use has been suggested in hypertension of pregnancy, since a similar drug, diazepam, has been used for this. Diazepam, however, crosses the placenta quickly and may accumulate in the fetus, concentrations in cord blood being higher than maternal values. ${ }^{1}$ This is associated with a high incidence of physiological depression when maternal doses exceed $30 \mathrm{mg}$, the babies being likely to have low Apgar scores, a tendency to apnoea, reluctance to feed, and impaired thermogenesis. ${ }^{2}$

Lorazepam has a half life of about 12 hours in adults, which is appreciably shorter than that of diazepam, and is predominantly metabolised to a pharmacologically inactive glucuronide. McBride et $a l^{3}$ reported that cord plasma concentrations of lorazepam were generally lower than the corresponding maternal concentrations, and this was confirmed

Division of Perinatal Medicine, Northwick Park Hospital and Clinical Research Centre, Harrow, Middlesex HA1 3UJ

A G L WHITELAW, MD, MRCP, consultant paediatrician

A J CUMMINGS, PHD, FRSC, pharmacologist

I R MCFADYEN, FRCOG, consultant obstetrician by Kanto et al. ${ }^{4}$ Those two studies, however, used fairly low doses in relatively uncomplicated cases. We have evaluated the effects of lorazepam in severe as well as mild hypertension and in preterm as well as full-term deliveries, as the drug appeared to have advantages over diazepam in obstetrics.

\section{Patients and methods}

Neonates delivered by two groups of pregnant women with hypertension and treated with lorazepam were studied and the results compared with those from infants born by elective caesarean section or delivered by mothers who had not had drug treatment apart from epidural analgesia. The first group of hypertensive women consisted of 35 who were admitted to hospital because their blood pressure was $140-150 / 90-100 \mathrm{~mm} \mathrm{Hg}$. If their blood pressure did not fall $\mathrm{N}$ below 140/90 mm $\mathrm{Hg}$ within 48 hours they were treated with oral N lorazepam in doses of $1 \mathrm{mg}$ twice daily to $2.5 \mathrm{mg}$ three times a day; seven were admitted before 28 weeks and also given labetalol. After delivery lorazepam was continued for 48-72 hours.

The second group comprised 16 women admitted because of fulminating hypertension. Their blood pressure ranged from 160/110 to $260 / 160 \mathrm{~mm} \mathrm{Hg}$, and $12 \mathrm{had}$ albuminuria. Lorazepam was given $\mathrm{O}$ by continuous infusion of $8 \mathrm{mg}$ in $500 \mathrm{ml} \mathrm{5 \%}$ dextrose and water, the rate being adjusted according to the patient's condition. Intravenous hydralazine was also given to all of these patients. None had received lorazepam or other sedatives before admission. Five were delivered vaginally and 11 by caesarean section.

The objectives of the study were to measure placental transfer of conjugated and unconjugated lorazepam under different clinical conditions, look for pharmacological effects in the newborn infant, study elimination of the drug by the baby, and measure its excretion in breast milk. For comparison with the treated groups there were 30 infants born by elective caesarean section at term and 101 delivered at term by mothers whose only drug treatment was epidural analgesia.

At 26 deliveries $10 \mathrm{ml}$ samples of blood from a maternal vein and the umbilical vein were taken into lithium heparin; a timed urine sample was collected from each baby every day that they remained in hospital. The separated plasma and urine were kept at $-20^{\circ} \mathrm{C}$ until analysed. Unconjugated and total lorazepam (conjugated + unconjugated) were measured by gas-liquid chromatography using a modification of the method of Greenblatt et al. ${ }^{5}$ Each baby's resting blood pressure was measured at about 12, 36, and 60 hours using a Doppler blood-flow detector, mercury sphygmomanometer, and a $5 \mathrm{~cm}$ paediatric cuff. Nurses recorded the Apgar score at birth, and the baby's rectal temperature was measured every four hours for 48 hours. The amount of milk that the baby took was recorded in $\mathrm{ml}$ in the case of bottle feeding; if the mother was breast feeding the time that the baby sucked from each breast was recorded. A baby was thought to have established satisfactory feeding if he or she could take $30 \mathrm{ml}$ of milk by sucking from a bottle or could suck effectively for three minutes from each breast.

\section{Results}

Plasma concentrations of lorazepam were slightly higher in maternal than in cord blood (fig 1): neither value was closely related to the dose. The high concentrations recorded in some patients reflected their fulminating hypertension, which required infusion of the drug at $1 \cdot 5-4.0 \mathrm{mg} /$ hour for satisfactory sedative and anticonvulsant effect. Relative concentrations of free and conjugated lorazepam reflected the duration of treatment. Mothers delivered within a few hours after starting intravenous lorazepam had little conjugated drug in their blood or in their infant's cord blood, whereas treatment for more than 24 hours was associated with a predominance of conjugated drug in both maternal and cord blood (table I). Cord blood tended to contain a slightly lower proportion of conjugated lorazepam than maternal. 
Lorazepam was eliminated gradually from the babies (fig 2). Full-term babies continued to excrete detectable amounts for at least eight days, and in preterm infants the glucuronide was still detectable in the urine at 11 days. Continued intake from breast milk was probably not responsible. One mother who was breast feeding required $2.5 \mathrm{mg}$ lorazepam twice daily for five days after delivery, and on the fifth day her milk contained $12 \mu \mathrm{g} / \mathrm{l}$ free and $35 \mu \mathrm{g} / \mathrm{l}$ conjugated lorazepam. If the maximum milk intake by the baby is assumed to have been $200 \mathrm{ml} / \mathrm{kg} /$ day the intake of lorazepam would

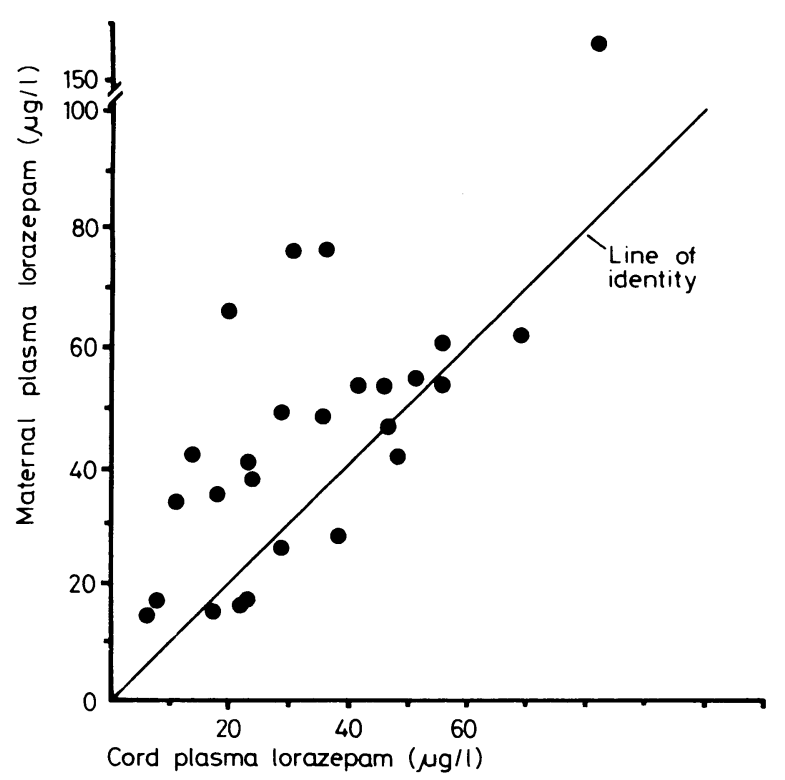

FIG 1-Simultaneous maternal venous plasma and umbilical venous plasma lorazepam concentrations from 26 infants.

TABLE I-Lorazepam and conjugated lorazepam in maternal and cord blood according to duration of treatment

\begin{tabular}{llccc}
\hline $\begin{array}{c}\text { Case } \\
\text { No }\end{array}$ & $\begin{array}{l}\text { Dose and } \\
\text { duration }\end{array}$ & $\begin{array}{c}\text { Lorazepam } \\
(\mu \mathrm{g} / 1)\end{array}$ & $\begin{array}{c}\text { Conjugated } \\
\text { lorazepam } \\
(\mu \mathrm{g} / 1)\end{array}$ & $\begin{array}{c}\text { Unconjugated } \\
\% \text { of total } \\
\text { lorazepam }\end{array}$ \\
\hline
\end{tabular}

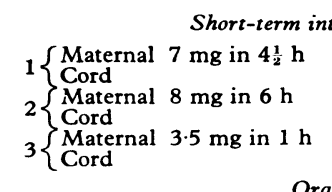

$\mathrm{h}$
$\mathrm{h}$
$\mathrm{h}$
Oral lorazepam

$\begin{array}{ll}41 & 53 \\ 48 & 11 \\ 55 & 82 \\ 46 & 26 \\ 48 & 39 \\ 36 & 6\end{array}$

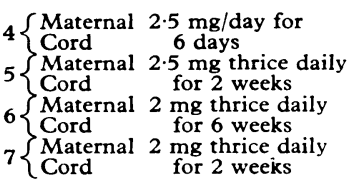

$44 \cdot 7$
$81 \cdot 3$

$40 \cdot 2$

$63 \cdot 8$

$55 \cdot 0$
$85 \cdot 8$

$33 \cdot 0$
$23 \cdot 9$
$32 \cdot 4$

$32 \cdot 4$
$54 \cdot 6$

$41 \cdot 9$

$47 \cdot 0$

$35 \cdot 7$
$28 \cdot 6$ have been $2.6 \mu \mathrm{g} / \mathrm{kg} /$ day. Had the infant absorbed all of the conjugated lorazepam the maximum intake would have been $9.6 \mu \mathrm{g} / \mathrm{kg} /$ day, while the lowest therapeutic dose corresponded to $28 \mu \mathrm{g} / \mathrm{kg} / \mathrm{day}$; this neonate did not show any sedative effect.

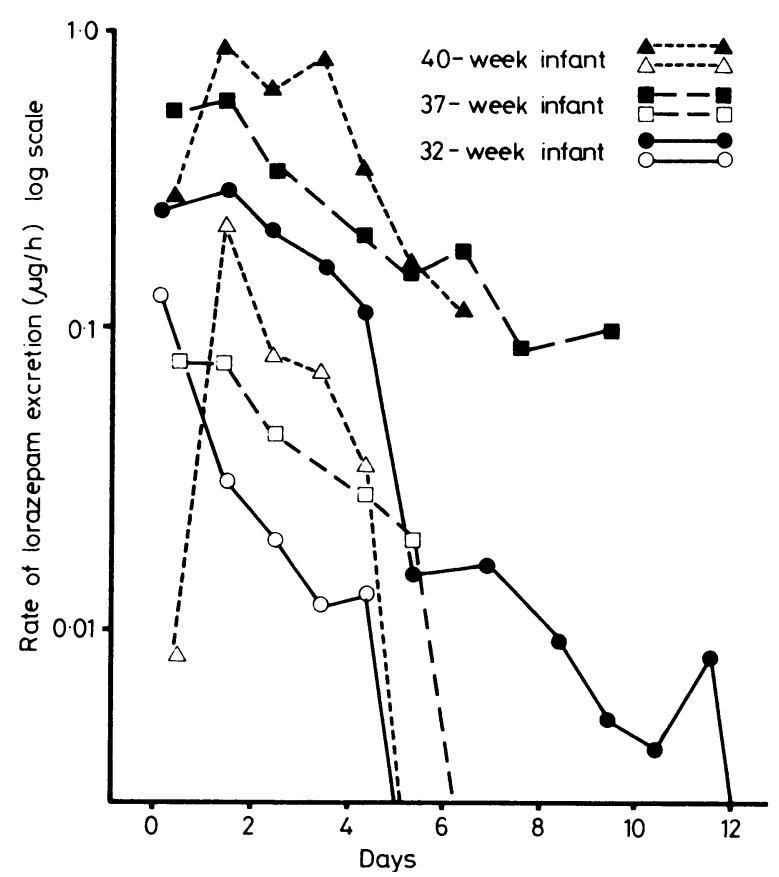

FIG 2-Neonatal excretion of lorazepam (open symbols) and conjugated lorazepam (closed symbols).

Table II shows the behaviour of babies born at term. Long-term oral treatment had little effect on the neonate apart from delay in establishing breast feeding, which was similar to the delay after elective caesarean section without other drugs. Intravenous lorazepam was similar to diazepam in reducing the Apgar score at delivery and increasing the necessity for intubation and ventilation. Both drugs were also associated with an increased incidence of neonatal hypothermia and poor suckling, which necessitated tube feeding. Among mothers given oral treatment the babies who had delayed establishment of feeding were all delivered from those receiving a mean dose of $5.5 \mathrm{mg} /$ day for a mean of 22 days.

Preterm neonates whose mothers were given lorazepam had a very high incidence of depressed respiration, hypothermia, and feeding problems: this was so by whichever route the drug had been given (table III). Diazepam was associated with a similar high incidence of these complications, though significantly fewer neonates had low Apgar scores at one minute. This may have been due to the higher mean birth weight and greater gestational age in the diazepam group, their mean birth weight being $394 \mathrm{~g}$ greater and gestational age one week more than the lorazepam group.

The need for intubation and ventilation at birth was clearly related to cord blood concentrations of lorazepam: eight neonates had $45 \mu \mathrm{g}$

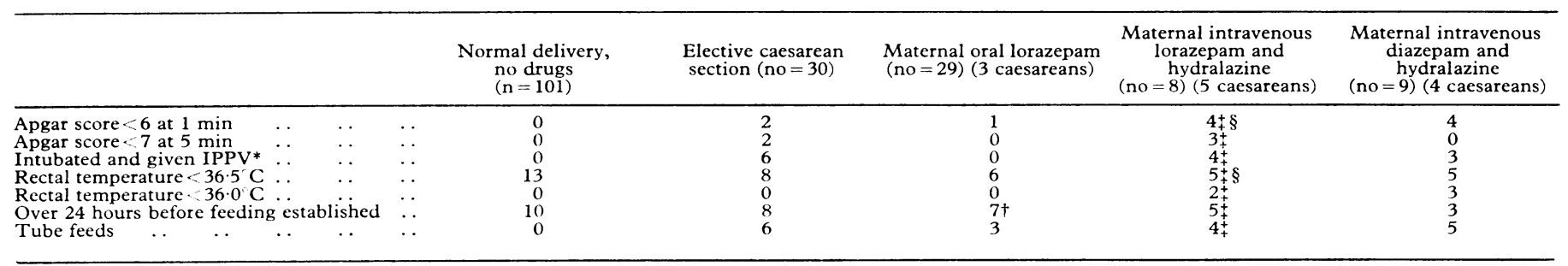

*IPPV = Intermittent positive-pressure ventilation.

p 0.05 compared with normal delivery and no drugs ( $\chi^{2}$ test).

p 0.01 compared with normal delivery and no drugs ( $x^{2}$ te 
lorazepam per 1 of cord blood, and six of these required intubation; out of 18 with cord blood concentrations below $45 \mu \mathrm{g} / \mathrm{l}$, however, only four needed intubation. This difference was significant $(p<0.05$; $\chi^{2}$ test). Neonatal resting blood pressures for the first three days of life were the same in babies from control mothers and those treated with oral lorazepam.

\section{Discussion}

We found that maternal lorazepam has some sedative effect on the neonate, despite cord blood concentrations of the drug being in general lower than corresponding maternal values. The main route of elimination in the neonate is by conjugation to lorazepam glucuronide and renal excretion. This mechanism
We emphasise that many of the mothers treated with lorazepam $\underline{\underline{w}}$ in our hospital had severe hypertension and certainly required some sedative and anticonvulsant agent. In our hospital no lorazepam-treated mother has developed eclampsia, whereas two women have had eclamptic fits during continuous intravenous infusions of diazepam. The effects that we observed in newborn infants could be serious in a poorly staffed obstetric unit but were not difficult to deal with in a perinatal centre with 24-hour availability of neonatal paediatricians. Of our series of 53 high-risk infants, only two died, weighing $540 \mathrm{~g}$ and $900 \mathrm{~g}$. Probably any therapeutic regimen for severe pre-eclampsia will result in some sedation of the neonate. Nevertheless, the potent effects on the neonate demand that the use of lorazepam intravenously and before 37 weeks of

TABLE III-Preterm infants

\begin{tabular}{|c|c|c|c|c|c|c|}
\hline & & & $\begin{array}{c}\text { Oral lorazepam } \\
\text { and hypotensive } \\
(n=7) \\
(1 \text { set of twins) }\end{array}$ & $\begin{array}{c}\text { Intravenous } \\
\text { lorazepam } \\
\text { and hypotensives } \\
(n=9)\end{array}$ & $\begin{array}{c}\text { All preterm infants } \\
\text { + lorazepam } \\
\text { + hypotensives } \\
(n=16)\end{array}$ & $\begin{array}{l}\text { Intravenous diazepam } \\
\text { and hypotensives } \\
(\mathrm{n}=14)\end{array}$ \\
\hline $\begin{array}{l}\text { Caesarean section } \\
\text { Apgar score }<6 \text { at } 1 \text { min } \\
\text { Apgar score }<7 \text { at } 5 \mathrm{~min} \\
\text { Intubation and IPPV } \\
\text { Temperature }<36.5^{\circ} \mathrm{C} \\
\text { Temperature }<36.0^{\circ} \mathrm{C} \\
\text { Over } 24 \text { hours before feedin } \\
\text { Tube feeds } . \\
\text { Mean birth weight } ¥ \mathrm{SD} \text {. } \\
\text { Mean gestational age } \pm \mathrm{SD} \\
\text { Mean drug dosage } \pm \mathrm{SD} \text { ( }\end{array}$ & 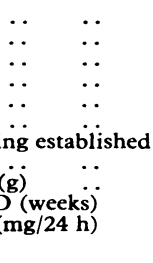 & $\begin{array}{l}\cdots \\
\cdots \\
\cdots \\
\cdots \\
\cdots \\
\cdots \\
\cdots \\
\cdots\end{array}$ & $\begin{array}{c}5 \\
6 \\
4 \\
4 \\
6 \\
3 \\
7 \\
7 \\
1511+532 \\
31 \cdot 9 \pm 3 \cdot 0 \\
5 \cdot 25 \pm 1 \cdot 9\end{array}$ & $\begin{array}{rl}7 \\
8 \\
5 \\
8 \\
9 \\
6 \\
8 \\
8 \\
1699+668 \\
32 \cdot 9 & 1 \cdot 7 \\
18 \cdot 0 & 8 \cdot 0\end{array}$ & $\begin{array}{r}12 \\
14 \\
9 \\
12 \\
15 \\
9 \\
15 \\
15 \\
1616+619 \\
32 \cdot 4+2 \cdot 6 \\
11 \cdot 1+9 \cdot 4\end{array}$ & $\begin{array}{c}10 \\
5 * \\
4 \\
6 \\
9 \\
10 \\
11 \\
11 \\
2010+810 \\
33 \cdot 5+3 \cdot 1 \\
69 \cdot 3+64 \\
\text { (diazepam) }\end{array}$ \\
\hline
\end{tabular}

* $p<0.01$ compared with all preterm infants + lorazepam

IIPPV = Intermittent positive-pressure ventilation.

is very slow, however, and in many babies lorazepam glucuronide may still be detectable seven days after birth. Low drug concentrations did not appear to be associated with obvious adverse effects in the baby, and sedation was apparent for only about 48 hours. The most serious adverse effect of maternal lorazepam treatment was an excess of low Apgar scores at one minute, and there appeared to be a link between high cord blood concentrations of the drug and Apgar scores below 6 at one minute, with the need for intubation and ventilation. High-dose intravenous lorazepam treatment, particularly in preterm deliveries, was also associated with hypothermia and delayed establishment of feeding. Lorazepam is not a specifically hypotensive drug, and there was no gross depression of neonatal blood pressure. Depressant effects on the baby were about the same as with diazepam, except that in preterm infants the diazepam group had slightly better Apgar scores at one minute than the lorazepam group. Mean birth weight and gestational age were greater in the preterm diazepam group than in the preterm lorazepam group, though this did not reach statistical significance. Thus the anticipated advantages of lorazepam over diazepam for the neonate were not confirmed in this study. Though lorazepam was detectable in breast milk using a sensitive assay, the amounts that a baby would ingest were so low as to be pharmacologically insignificant. gestation should be restricted to hospitals with facilities for neonatal intensive care.

We acknowledge the help of Sister Cathy Lawrence in this study and the co-operation of nursing staff in the delivery suite, postnatal wards, and special-care baby unit, Northwick Park Hospital.

\section{References}

1 Gamble JAS, Moore J, Lamka $\mathrm{H}$, Howard PJ. A study of plasma diazepam levels in mother and infant. Br $\mathcal{F}$ Obstet Gynaecol 1977;84:588-91.

${ }^{2}$ Cree JE, Meyer K, Hailey DM. Diazepam in labour. Its metabolism and effect on the clinical condition and thermogenesis of the newborn. Br Med F 1973;iv:251-5.

${ }^{3}$ McBride RJ, Dundee JW, Moore J, Toner W, Howard PJ. A study of the plasma concentrations of lorazepam in mother and infant. $\mathrm{Br} \mathbf{F}$ Anaesth 1979;51:971-7.

4 Kanto J, Aaltonen L, Linkka P, Maenpaa K. Transfer of lorazepam and its conjugate across the human placenta. Acta Pharmacol Toxicol (Copenh) 1980;47:130-4.

${ }^{5}$ Greenblatt DJ, Franke K, Shader RI. Analysis of lorazepam and its glucuronide by electron-capture gas-liquid chromatography. f Chromatogr 1978;146:311-20.

(Accepted 5 February 1981) 